\title{
GRAVITATIONAL STRESSES IN FLOATING ICE SHEETS
}

\author{
By R. J. Evans \\ (Department of Civil Engineering, University of Washington, Seattle, Washington 98r95, U.S.A.) \\ and R. ReID PARMerter \\ (Department of Aeronautics and Astronautics, University of Washington, Seattle, Washington 98195, \\ U.S.A.)
}

\begin{abstract}
This note is addressed to the determination of the in-plane components of stress in floating ice sheets due to gravity and the hydrostatic pressure in the water. The distribution and magnitude of these stresses are of interest with regard to crack propagation in sea ice. Two cases are considered. In the first, the ice sheet is formed on land by accretion at the top surface and then introduced into the water, such as happens in the Antarctic. In the second, the ice is formed in the water by accretion on the bottom, which is the usual situation in the Arctic pack ice.

RÉsumé. Contraintes de gravité dans les banquises. Cette note a pour but de déterminer les composantes horizontales des efforts qui se produisent dans les banquises flottantes du fait de la gravité et de la pression hydrostatique dans l'eau. La distribution et l'ordre de grandeur de ces efforts sont intéressantes pour l'étude de la propagation des fissures dans la glace de mer. On considère deux cas. Dans le premier cas, la banquise est formée sur le continent par apport en surface, puis introduite dans l'eau. Sous certaines conditions, cette représentation convient pour les glaces flottantes de l'Antarctique. Dans le second cas, la glace se forme dans l'eau par apport par le dessous de la banquise, c'est la situation ordinaire dans le pack Arctique.

Zusammenfassung. Schwerkraftspannungen in schwimmenden Eistafeln. Diese Notiz gilt der Bestimmung der ebenen Spannungskomponenten in schwimmenden Eistafeln infolge der Schwerkraft und des hydrostatischen Drucks im Wasser. Die Verteilung und Grösse dieser Spannungen sind im Hinblick auf die Fortpflanzung von Brüchen in Meereis von Interesse. Zwei Fälle werden betrachtet: Im ersten bildet sich die Eistafel an Land durch Zuwachs an der Oberfläche und kommt dann ins Wasser. Unter gewissen Bedingungen gilt diese Idealisierung für die schwimmenden Eistafeln von Antarktika. Im zweiten entsteht das Eis im Wasser durch Aufwachsen an der Unterseite, was den Verhältnissen im arktischen Packeis entspricht.
\end{abstract}

\section{INTRODUCTION}

The in-plane components of stress in floating ice sheets depend upon the loads, the constitutive behavior of the ice, and the manner in which the ice was formed. The basic loading due to gravity and hydrostatic pressure is considered in this note. The constitutive behavior of the ice is assumed to be elastic and isotropic. Evidence suggests that the actual behavior is visco-elastic. If this visco-elasticity is Maxwellian, the state of stress will eventually become that of a fluid, i.e. hydrostatic, and the results of this note apply only on a short time scale. In fact, sea ice does not appear to reach isostatic equilibrium with time. This is illustrated both by measured upper and lower surface profiles (Weeks and others, [1972]) and by the observed relative vertical displacements of newly formed cracks (A. S. Thorndike, personal communication). Thus the visco-elastic behavior is probably more accurately modeled as a Kelvin solid and the results presented will apply on both short and long time scales using the Poisson ratio corresponding to the short- and long-term properties, respectively.

The water provides an elastic support for the ice sheet. This support is accurately modeled in static problems as a Winkler foundation (Hetényi, 1946). When bending loads are applied to a plate on an elastic foundation, the bending deformation and stresses are exponentially damped by the foundation with a characteristic length given by

$$
\left(D / \rho_{\mathrm{w}} g\right)^{\frac{1}{4}},
$$

where $\rho_{\mathrm{w}}$ is the density of water and $D$ is the bending stiffness of the ice sheet. Thus the effect of moments applied to the edge of the sheet is rapidly damped, and only the resultant in-plane forces at the edges need be considered when calculating stress fields at points that are several characteristic lengths from the edge.

\section{CASE I. ICE FORMED BY ACCRETION AT THE TOP}

During the accretion process the ice forming at the surface does so at zero stress. At a depth $z$, however, the gravity stress resulting from the total accretion process is given by

$$
\sigma_{z}=-\rho_{\mathrm{i}} g z
$$


where $\rho_{1}$ is the density of ice. The vertical stress plus the restraint on transverse strain leads to in-plane stresses.

$$
\sigma_{x}=\sigma_{y}=-\frac{\nu}{\mathrm{I}-\nu} \rho_{\mathrm{i}} g z,
$$

where $\nu$ is the Poisson ratio and $x$ and $y$ are in-plane Cartesian coordinates. Subsequently, $\sigma_{x}$ and $\sigma_{y}$ will be denoted by $\sigma$. The stresses given by Equation (I) are obtained regardless of whether the history of loading during growth of the ice is considered or gravity is simply assumed to act after the ice sheet has formed (Brown and others, 1972).

When the ice is introduced into the water, the lateral constraint is replaced by a lateral pressure at the edge. The stress on the edge is shown in Figure ra. Here, $H$ is the thickness of ice below the water and

$$
\alpha=\frac{\rho_{\mathrm{w}}-\rho_{\mathrm{i}}}{\rho_{\mathrm{i}}} .
$$

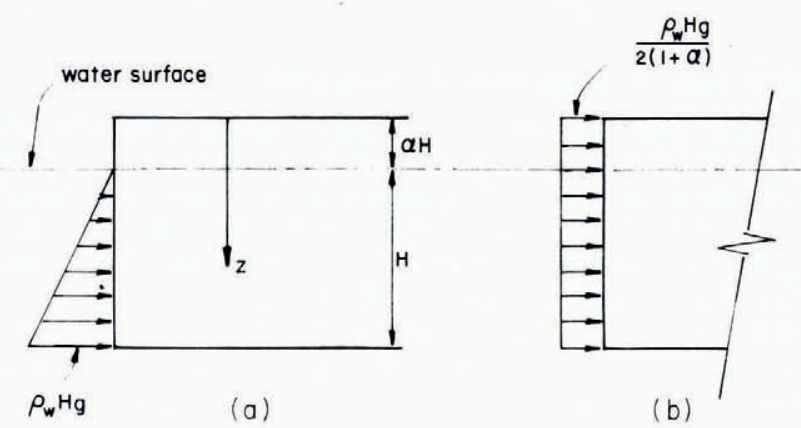

Fig. I. In-plane hydrostatic stress.

This stress is statically equivalent to a moment and an in-plane force. Due to the elastic foundation, only the resultant force propagates away from the boundary; the corresponding stress at points remote from the edge is shown in Figure $\mathrm{Ib}$. The release of lateral restraint also generates a uniform stress through the thickness of the sheet. Superimposing a uniform stress and the stress of formation ( $\mathrm{I}$ ), and using the condition of force equilibrium with the edge stress (Fig. Ib), the lateral stress in the floating sheet is found to be

$$
\sigma=-\frac{\mathrm{I}}{2} \rho_{\mathrm{i}} g H\left[\mathrm{I}-\nu \frac{(\mathrm{I}+\alpha)}{\mathrm{I}-\nu}\right]+\frac{\nu}{\mathrm{I}-\nu} Z .
$$

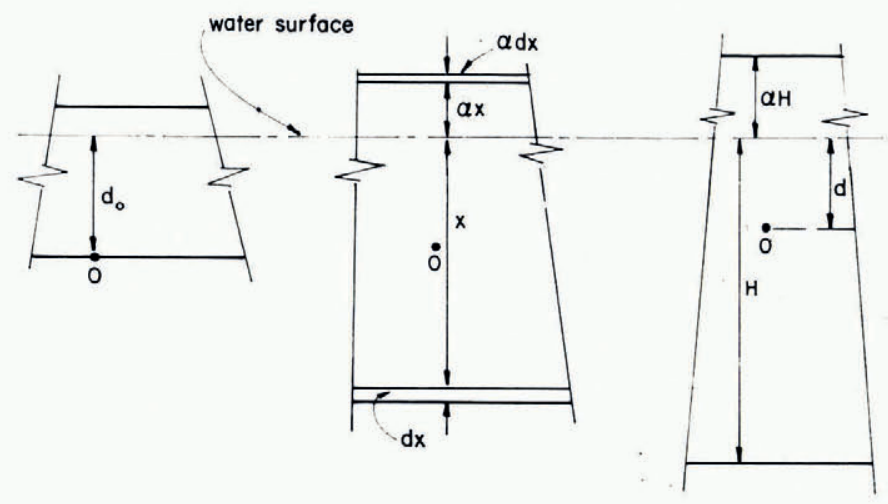

(a)

(b)

(c)

Fig. 2. Growth of an ice sheet. 


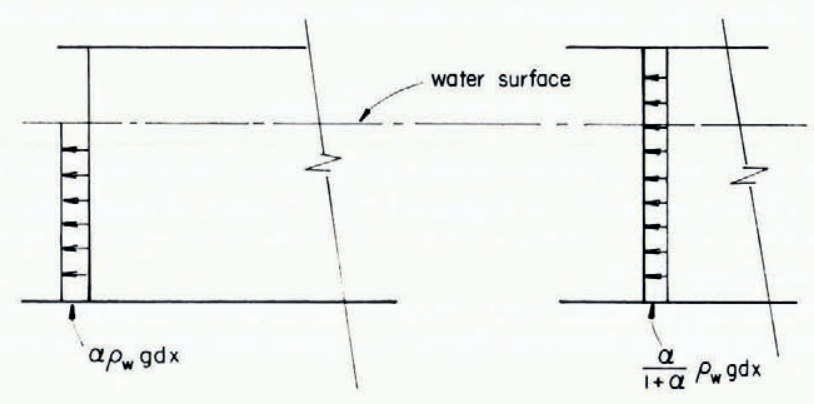

(a)

(b)

Fig. 3. Incremental stress in ice sheet.

CASE 2. FloAting ice formed by ACCRETion at the bottom

In the case of floating ice which accretes at the bottom, the ice is formed under conditions of hydrostatic pressure. Referring to Figure 2, consider the particle that first froze at depth $d_{0}$, with a hydrostatic stress $-d_{0} \rho_{\mathrm{w}}$. The final transverse stress on the particle is given by $-d_{0} \rho_{\mathrm{w}}$ plus the added stress as the ice sheet continues to grow to its final thickness $(\mathrm{I}+\alpha) H$. Consider now the intermediate position (Fig. 2b). As the depth below the water increases by $\mathrm{d} x$, the surface (and hence point $\mathrm{o}$ ) has risen by $\alpha \mathrm{d} x$ and the stress there has changed due to the reduction of hydrostatic pressure. The reduction in pressure at the ends of the sheet due to this rise is shown in Figure 3a. Replacing this stress distribution by an equivalent uniform pressure and flexure, only the uniform pressure propagates away from the ends (Fig. 3 b) and the incremental reduction in compressive stress at $o$ is given by

$$
\mathrm{d} \sigma=\rho_{\mathrm{w}} g \frac{\alpha}{\mathrm{I}+\alpha} \mathrm{d} x .
$$

Thus the stress at $o$ in the final ice-sheet configuration is given by

$$
\sigma(d)=-\rho_{\mathrm{w}} g d_{0}+\int_{x=d_{0}}^{x=h} \mathrm{~d} \sigma .
$$

Making use of the relation

$$
d_{0}=\frac{d+\alpha H}{\mathrm{I}+\alpha}=\frac{z}{\mathrm{I}+\alpha},
$$

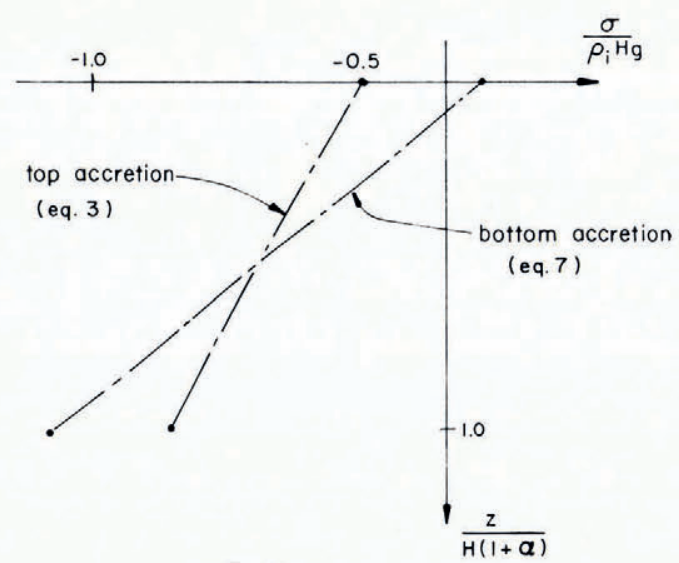

Fig. 4. Lateral stress in ice $\nu=\frac{1}{3}, \alpha=\frac{1}{10}$. 
with Equations (2) and (4), Equation (5) becomes

$$
\sigma=\frac{\rho_{\mathrm{i}} g}{\mathrm{I}+\alpha}[(\mathrm{I}+2 \alpha) z-\alpha(\mathrm{I}+\alpha) H] .
$$

The stress distributions given by Equation (3) for case 1 and Equation (7) for case 2 are quite different, as is seen from Figure 4. In particular, tensile stress occurs at the top surface of the ice for the bottom accretion case. For typical Arctic sea ice, this stress is small in comparison with the tensile strength of the ice. The question of whether or not such a stress is a significant factor in fracture cannot be answered until more information is available on the fracture toughness of sea ice. At the bottom surface, compressive stresses that occur in both cases have a significant effect in retarding crack growth from that surface.

\section{AcKNowledgement}

This research was supported in part by National Science Foundation Grant OPP $71-04031$ with the University of Washington. The grant is a part of AIDJEX (Arctic Ice Dynamics Joint Experiment).

MS. received 5 February 1977 and in revised form 20 October 1977

\section{REFERENCES}

Brown, C. B., and others. 1972. Slab avalanching and the state of stress in fallen snow, [by] C. B. Brown, R. J. Evans and E. R. LaChapelle. Fournal of Geophysical Research, Vol. 77, No. 24, p. 4570-80.

Hetényi, M. 1946. Beams on elastic foundation. Ann Arbor, University of Michigan Press.

Weeks, W. F., and others. [1 972.$]$ Pressure ridge characteristics in the Arctic coastal environment, by W. F. Weeks, A. Kovacs and W. D. Hibler, III. (In Wetteland, S. S., and Bruun, P., ed. Proceedings, the first International Conference on Port and Ocean Engineering under Arctic Conditions. The Technical University of Norway, Trondheim, Norway, Aug. 23-30, I971. [Trondheim, Technical University of Norway], Vol. I, p. I52-83.) 